\title{
Enhancing English Language Vocabulary Learning among Indigenous Learners through Google Translate
}

\section{Ting Fang Kai ${ }^{1}$ Tan Kim Hua ${ }^{2}$}

${ }_{12}^{2}$ Faculty of Education, Universiti Kebangsaan Malaysia, Malaysia. Email:tfangkai@gmail.com Tel: +60168908259 Email:kimmy@ukm.edu.my Tel: +60192735440

\section{Abstract}

The emergence of new technologies has brought massive changes to teaching and learning processes. In recent years, mobile phones have evolved into effective teaching tools; when used practically, they could improve learning outcomes. The potential of mobile phones as a learning platform has led to a proliferation of research into their effectiveness. This paper aims to examine the effectiveness of the Google Translate mobile application (hereinafter "app") in improving indigenous learners' English language vocabulary. Fifteen Iban participants with low English language proficiency from rural schools were chosen through purposive sampling. The data were collected by comparing scores in the pre-test and post-test. In addition, the data were triangulated through structured interviews. Key findings indicated that almost all participants achieved high scores in the post-test. The interviews also revealed that all participants affirmed that Google Translate supports their English language proficiency, and only one participant was unsure of its effectiveness. Thus, the findings of this study imply that Google Translate could be an effective teaching tool to enhance learners' English language vocabulary. Future research could examine the effectiveness of the app in teaching vocabulary in different contexts.

Keywords: Google translate, Vocabulary, English education, Indigenous learner, Rural, Primary school.

Citation | Ting Fang Kai; Tan Kim Hua (2021). Enhancing English Language Vocabulary Learning through Google Translate Mobile Application among Indigenous Learners. Journal of Education and e-Learning Research, 8(2): 143-148.

History:

Received: 14 January 2021

Revised: 4 February 2021

Accepted: 26 February 2021

Published: 18 March 2001

Licensed: This work is licensed under a Creative Commons Attribution 3.0 License (c))

Publisher: Asian Online Journal Publishing Group
Acknowledgement: Both authors contributed to the conception and design of the study.

Funding: This study was supported by the Malaysian Ministry of Higher Funding: This study was supported by the Malaysian Min
Education Re-search Grant FRGS/1/2018/SS09/UKM/02/1

Competing Interests: The authors declare that they have no conflict of interests.

Transparency: The authors confirm that the manuscript is an honest, accurate, and transparent account of the study was reported; that no vital features of the study have been omitted; and that any discrepancies from the features of the study have been omitted;
study as planned have been explained.

Ethical: This study follows all ethical practices during writing.

\section{Contents}

1. Introduction 


\section{Contribution of this paper to the literature}

Very few studies have examined the impact of utilizing the Google Translate mobile app to enhance English vocabulary learning, particularly among primary school students in rural areas. Due to its speed, most learners in rural areas have resorted to Google Translate when completing their class assignments in a second language. The findings of this research confirm the efficacy of Google Translate as an alternative learning tool in teaching vocabulary in rural areas of Malaysia.

\section{Introduction}

The emergence of new technologies has brought major changes to learning and teaching processes (Pavlik, 2015). Among these, language teaching practices have also been influenced by this technological paradigm shift (Stockwell, 2010). Rafiq, Hashim, Yunus, and Norman (2020), for instance, reported the effectiveness of Massive Open Online Courses (MOOC) as a potentially appropriate learning environment. By offering practical, flexible, and personalized learning opportunities outside the classroom, mobile learning has significantly changed traditional teaching approaches (Rafiq et al., 2020). In fact, the wide, touch-sensitive screens of modern smartphones provide greater possibilities for learning and teaching compared to pre-smartphone mobile devices (Kukulska-Hulme \& Traxler, 2005). Moreover, the use of modern technologies can help teachers to be creative to encourage students to practice their English skills such as writing, speaking, reading, and listening (Philip, Tan, \& Jandar, 2019). To master these skills, students must establish a good foundation of fundamental English components, such as grammar, pronunciation, and vocabulary.

Vocabulary is considered a complex endeavor, the mastery of which is difficult for most learners (Stockwell \& Liu, 2015). The complexity of word forms, word choices, and various meanings (González Fernández \& Schmitt, 2015; K. H. Tan et al., 2020) presents difficulties for learners trying to master English vocabulary. Recently, various translation applications (hereinafter "apps") have been developed, and they are being adopted by learners as an alternative tool for mastering English vocabulary. Google Translate is one app that uses online machine translation (MT) tools in multi-language translation processes (Graesser et al., 2014).

Google Translate has been improved and currently offers multiple definitions of a word in the field below the main input. Giannetti (2016) contends that this development has significantly improved the app's efficacy in the translation of adjectives, nouns, and adverbs. Nonetheless, Google Translate has limitations in the area of transitive verbs, particularly in non-Romance languages. Given that English does not have unique conjugations for most verbs and depends mainly on auxiliary verbs in constructing tenses, Google Translate offers a practical tool for teaching vocabulary to primary school learners. Thus, this study aims to investigate the relationship between the use of Google Translate and improvements in pupils' vocabulary learning.

\section{Literature Review}

\subsection{Vocabulary Learning Strategies in a Second Language}

Vocabulary learning is central to the development of proficiency and the achievement of competency in the target language. Hence, researchers are continually seeking the best technique for teaching vocabulary. On the one hand, English learning strategies can be categorized into four groups, namely, cognitive, metacognitive, affective, and social (Chen, 2016; Hsiao, Lan, Kao, \& Li, 2017). On the other hand, the vocabulary learning process can be divided into structured and unstructured approaches, according to Sanaoui (1995). Xie (2010) argued that structured learning approaches are perceived to be more productive, whereas unstructured learning approaches are surplus to the learning process. Moreover, structured learning often provides more systematic approaches to the organization and handling of study materials.

Earlier studies by Gu and Johnson (1996) highlighted that learning English as a second language is often focused on rehearsal strategies, and previous studies have addressed questions such as the maximum number of words that can be learnt at one time (Nakata \& Webb, 2016) and the number of repetitions required to learn a list (Anderson \& Jordan, 1928). However, silent writing and silent repetition appeared to be less effective than the spoken repetition of words (Candry, Deconinck, \& Eyckmans, 2018). Furthermore, Gu and Johnson (1996) posited that rote repetition appeared to be a less effective learning strategy than spaced recall and structured reviews. Spaced recall and structured reviews have been proven to be effective vocabulary learning strategies.

The process of learning English as a second language has been copiously studied over the past four decades (Farashaiyan \& Tan, 2012; Tan, Farashaiyan, Sahragard, \& Faryabi, 2020). Previous studies by Atkinson (1975) and Atkinson and Raugh (1975) on the subject centered on the keyword method, a technique that begins by introducing an acoustic link (e.g., finding a key word in the learners' first language (L1) that sounds like the foreign word) through an interactive image. Gu and Johnson (1996) in particular argued that most previous studies overlook the use of $\mathrm{L}_{1}$ - one of the most essential attributes of second-language learners that make them fundamentally different from mother-tongue vocabulary learners.

Studies have highlighted the fact that learners comprehend a question posed to them by inferring the meaning from the question's structure, as well as by referring to other resources (Saigh \& Schmitt, 2012). In another study, Chang, Liu, and Paas (2018) examined the impact of the use of computer-aided dictionaries and suggested that "definition checking" enhances learners' memory, hence facilitating the learning of English as a second language (Tan, 2009). The participants learnt by looking up definitions in computer-aided dictionaries. Current studies on vocabulary strategies, which have been aligned with experts' opinions, aim to associate new words with the learner's mother-tongue by the student first guessing and then checking their definition.

\subsection{Vocabulary Acquisition through Mobile Applications}

The numerous studies on the implementation of mobile learning strategies in language learning have reported mixed findings, although the majority of studies report positive acceptance by learners (Al-Said, 2015). Suwantarathip and Orawiwatnakul (2015) conducted a comparative study between the outcomes of conventional in-class paper-based vocabulary teaching and learning and the use of Short Message Service (SMS) technology outside the classroom. They found that participants who used the SMS approach performed better than those who 
used conventional classroom settings. Similarly, Saran and Seferoğlu (2010) conducted a study on a group of students, comparing the use of SMS with audio and images, with the use, by the control group, of traditional classroom resources and dictionaries. Their findings revealed that the students who used SMS obtained higher test scores than the control group. Other studies on the use of mobile phones for vocabulary learning have also demonstrated positive results in terms of learners' experience and acceptance (Basal, Yilmaz, Tanriverdi, \& Sari, 2016; Wijaya, Bakri, Wutun, Fitriani, \& Mattoliang, 2019). Mobile phones enhance learning, as their use aligns with learners' preferred learning style (Shuib, Abdullah, Azizan, \& Gunasegaran, 2015). To ensure the mobile applications can be fully utilized, Eppard, Hojeij, Ozdemir-Ayber, Rodjan-Helder, and Baroudi (2019) encourage the use of portable devices with quick processors. Despite positive acceptance rates by learners, Deris and Shukor (2019) caution that there are challenges in using mobile devices as a tool for language learning. In fact, the use of mobile phones in classrooms is still restricted and, in most cases, teachers discourage students from using mobile phones in class. Nevertheless, evidence suggests that the use of mobile apps in learning English as a second language offers significant advantages; therefore, the use of mobile apps in learning cannot be disregarded, despite the limitations.

\subsection{Google Translate in Vocabulary Learning}

Google Translate provides a general definition of words; hence, learners who use it may have varying interpretations of the meaning of the word. One the one hand, the use of Google Translate in teaching and learning English may be practical when it is employed as the first tool for finding the definition of one or more unfamiliar words. On the other hand, Oktaviana (2018) argued, after carrying out a thorough analysis of the output, that Google Translate may not be an appropriate tool in advanced learning, unless it is supported by human translation.

Josefsson (2011) investigated the use of Google Translate in the learning strategies of vocational training students. The study found that, as a supporting tool on learners' mobile phones, Google Translate performed much better than traditional tools such as dictionaries. Moreover, Google Translate provided high accuracy and speed, especially in the translation of collocations, phrases, and technical words.

Groves and Mundt (2015) used a sample of students on an English academic writing course. The authors asked participants to write an essay in their native language and to translate it to English using Google Translate. Despite errors and limitations, the translations generated by Google Translate were comprehensible and close to the minimum level required by most learning institutions for university admission.

According to Ducar and Schocket (2018), the use of Google Translate improves students' mastery of English spelling. According to the authors, Google Translate does not only identify spelling mistakes, but also corrects students' original spelling errors. A paper submitted with typographical errors in the original language once signaled that a student had made use of MT. However, this implication is often no longer true. Google Translate now corrects high-frequency typographical errors and suggests the word or idea that is intended by the user instead of reproducing the user's error. Google Translate has also shown its effectiveness at close-range gender and number agreement, although its ability to maintain agreement across subordinated clauses weakens as the distance from the source increases (Ducar \& Schocket, 2018).

\section{Methodology}

\subsection{Research Design}

This study aims to improve the teaching and learning process by gathering relevant information through action research. This involved conducting four steps, namely planning, acting, observing, and reflecting. In the planning stage, all relevant previous studies that focused on vocabulary teaching and the use of Google Translate in the learning context were scrutinized. The teaching experience in the school was reflected on, and insight was gained from discussions with the senior English language teachers. Google Translate was used as a learning tool during phase 7 of the Recovery Movement Control Order. The use of Google Translate was conducted in accordance with the practicalities of time, resources, and the participants' willingness. The participants worked with the researcher over a period of approximately three weeks while completing Modules 5 through 7 . As a pretest, Module 5 was completed by participants without particular guidance, using only a traditional dictionary. Following the pre-test, the participants were instructed in the use of Google Translate to complete the Module. The results then served as a post-test. The steps were repeated for Modules 6 and 7. Finally, the data was analyzed to answer the research questions on the effectiveness of using Google Translate in teaching vocabulary.

\subsection{Research Participants}

Fifteen Iban students from Year 4, composed of eight female and seven male students, were chosen through purposive sampling. They were chosen on the basis of the homogeneity of their level of English proficiency. The range of scores in their summative tests are between $20 \%-40 \%$, indicating a passing yet low level of proficiency. Their demographic information is as similar as possible. They are all from specific longhouses, where many families live together, located in the same location. Moreover, their caregivers are mainly farmers and fishermen. Thus, the demographic data of the participants does not vary much.

\subsection{Research Instruments}

Pre-tests and post-tests were conducted for each of the Modules 5 through 7. Each module tasked participants to fill in missing letters. The vocabulary used in the modules was all based on the Get Smart Plus 4 textbook of the Common European Framework of Reference, thus enhancing the face reliability of the tests. In addition, the modules were adopted from an online teaching resource database for Sarawak English language teachers so as to match the comprehension level of the rural school's Iban participants. To enhance the reliability of the test, three experts from the same district were invited to revise the modules. The modules were then pilot-tested by a group of students to test the validity of the test. These students shared identical demographic information with the participants. The feedback from these students was carefully analyzed to further enhance the reliability and validity 
of the test. The differences between the pre-test and post-test scores were tabulated to answer the research objectives of determining the effectiveness of Google Translate as a teaching tool.

To shed more light on the research question, structured interviews were also carried out with the 15 participants. The interview questions were adopted from Lin and $\mathrm{Wu}$ (2016) and Kruk and Zawodniak (2018). Adjustments were made in accordance with participants' level of comprehension and to tally with the research question. The duration of each interview was approximately 15 minutes. Throughout the interview, the interviewer asked questions in English and then in Malay. Participants responded according to their ability, either in Malay or Iban, or a mixture of both languages. Thematic analysis was then applied to excerpts of the interviews to analyze the effectiveness of Google Translate in learning vocabulary. The procedures for analyzing and coding the responses were adopted precisely from Maguire and Delahunt (2017). Throughout the process of coding and categorizing the transcript themes, the researcher worked with two experts who were qualified to translate all languages involved. The transcript of the data was back-translated to prevent bias in interpretation.

\section{Findings}

\subsection{Module Pre-Test and Post-Test}

Table 1 shows the difference between the pre-test and post-test results collected from Module 5 to Module 7. Participants' identities were kept confidential. Each column shows the difference between the pre-test and post-test scores. The last column indicates the mean score difference.

\begin{tabular}{|c|c|c|c|c|}
\hline Participant (Pseudonym) & Module 5 & Module 6 & Module 7 & Mean score \\
\hline Bahie $(\mathrm{F})$ & $+15 \%$ & $+20 \%$ & $+30 \%$ & $+21.67 \%$ \\
\hline Gracessia $(\mathrm{F})$ & $+10 \%$ & $+30 \%$ & $+20 \%$ & $+20.00 \%$ \\
\hline Demai $(\mathrm{F})$ & $+25 \%$ & $+25 \%$ & $+30 \%$ & $+26.67 \%$ \\
\hline Lemba $(\mathrm{F})$ & $+15 \%$ & $-20 \%$ & $+30 \%$ & $+8.33 \%$ \\
\hline Jemat (M) & $+15 \%$ & $+25 \%$ & $+15 \%$ & +18.33 \\
\hline Andrew $(\mathrm{M})$ & $+15 \%$ & $+20 \%$ & $+20 \%$ & $+18.33 \%$ \\
\hline Cindy $(\mathrm{F})$ & $+10 \%$ & $\mathrm{O}$ & $+15 \%$ & $+8.33 \%$ \\
\hline Audrey $(\mathrm{F})$ & $+20 \%$ & $+15 \%$ & $+15 \%$ & $+16.67 \%$ \\
\hline Premaspay (M) & $+15 \%$ & $+35 \%$ & $+25 \%$ & $+25 \%$ \\
\hline Oliver $(\mathrm{M})$ & $+5 \%$ & $+10 \%$ & $+20 \%$ & $+11.67 \%$ \\
\hline Luta (M) & $+15 \%$ & $+15 \%$ & $-5 \%$ & $+8.33 \%$ \\
\hline $\operatorname{Demit}(\mathrm{F})$ & $-5 \%$ & $+30 \%$ & $+5 \%$ & $+10 \%$ \\
\hline Emylia $(\mathrm{F})$ & $+10 \%$ & $\mathrm{O}$ & $+35 \%$ & $+15 \%$ \\
\hline Undi (M) & $+10 \%$ & $+25 \%$ & $+30 \%$ & $+21.67 \%$ \\
\hline Rimong (M) & $+10 \%$ & $+15 \%$ & $\mathrm{O}$ & $+8.33 \%$ \\
\hline
\end{tabular}

The results show that in Module 5 almost all participants improved their score by a minimum of 10 marks, and only one participant obtained a lower score. Nonetheless, the decrease was merely 5 marks. In Modules 6 and 7, 13 out of 15 participants showed improvement, up to a maximum of 35 marks. The most impressive result is that all participants showed a mean improvement in marks in the post-test of the modules overall. Thus, the results suggest that Google Translate helps to improve participants' learning of English language vocabulary.

\subsection{Structured Interview}

Structured interviews were conducted with each of the 15 participants individually to triangulate the data. Table 2 shows excerpts from the interviews.

Table-2. Excerpts from the participants.

\begin{tabular}{c|l|c}
\hline Theme & Excerpts & Frequency \\
\hline English efficiency & I can try and guess. & 2 \\
\hline & The words are almost the same as Malay. & 6 \\
\hline & Easy to understand. & 4 \\
\hline Learning convenience & Help my friends check. & 7 \\
\hline & Very fast. & 5 \\
\hline & Time-saving. & 1 \\
\hline
\end{tabular}

Table 2 shows excerpts from students' answers to the research questions of this study. The transcripts of the interviews with the participants were interpreted and categorized into two main themes, namely English efficiency and learning convenience. The most frequent excerpt was that translated words are within the comprehension level of participants. Some participants claimed that using Google Translate in peer checking helps their vocabulary retention. Moreover, three participants discovered that some translated words were identical with their mothertongue words. They highlighted that the spellings are similar, and this encouraged them to guess the words. Previously, participants had paid no attention to the words. However, Google Translate compelled them to examine the words and engaged them in the learning process. The convenience of Google Translate could be the factor that encouraged English vocabulary retention among participants. Almost half of the participants highlighted that Google Translate is efficient in accessing the definition of words. The ease of use encourages them to learn vocabulary voluntarily. 


\section{Discussion}

The positive mean score difference found when comparing the pre-test and post-test data showed the significance of Google Translate in enhancing vocabulary learning. The mean score was then triangulated through structured interviews, which revealed two main factors that help learners to acquire new words. First, the interviewees' mother tongue aids vocabulary learning. This insight is consistent with Gu and Johnson (1996), who argued that educators overlook the role of the mother tongue in second language acquisition. They claimed that, if used appropriately, the mother tongue can aid learners with the acquisition of new vocabulary. Thus, educators could utilize learners' mother tongues to maximize learning outcomes. Secondly, the interviewees revealed that guessing key words is another factor that facilitates learning. Saigh and Schmitt (2012) reported that vocabulary learning takes place when the participants realize the identical spelling of targeted words with their first language. In addition, the results of the current study are consistent with Chang et al. (2018), who noted that definition checking in computer aided dictionaries encouraged learners' memory retention. A previous study by Deris and Shukor (2019) disagreed with the utilization of Google Translate in the case of advanced learners. In contrast, more studies support the use of Google Translate in learning, regardless of the proficiency level of the learners (Basal et al., 2016; Shuib et al., 2015; Wijaya et al., 2019). Moreover, Saran and Seferoğlu (2010) stated that digital tools could bridge the gap between remedial learners and advanced learners. Therefore, the Google Translate app could serve as an effective tool in teaching vocabulary to English language learners.

\section{Conclusion}

This paper aimed to examine the effectiveness of Google Translate in enhancing the vocabulary learning of Malaysian learners of English. The findings reported positive results through the difference between a pre-test and a post-test. Moreover, the excerpts from structured interviews with participants suggested the effectiveness of Google Translate in facilitating vocabulary learning. This result implies that English language teachers could utilize Google Translate in their lessons to encourage peer assessment and learner-centered learning. Current studies are focused on teaching vocabulary out of context. In the future, researchers could explore the possibility of adapting the app to teach vocabulary in context.

\section{References}

Al-Said, K. M. (2015). Students' perceptions of Edmodo and mobile learning and their real barriers towards them. Turkish Online Journal of Educational Technology, 14(2), 167-180.

Anderson, J. P., \& Jordan, A. M. (1928). Learning and retention of Latin words and phrases. Journal of Educational Psychology, 19(7), 485496.Available at: https://doi.org/10.1037/ho073011.

Atkinson, R. C. (1975). Mnemotechnics in second-language learning. American Psychologist, 30(8), 821.Available at: https://doi.org/10.1037/ho077029.

Atkinson., R. C., \& Raugh, M. R. (1975). An application of the mnemonic keyword method to the acquisition of a Russian vocabulary. Journal of Experimental Psychology: Human Learning and Memory, 1(2), 126-133.Available at: https://doi.org/10.1037/0278-7393.1.2.126.

Basal, A., Yilmaz, S., Tanriverdi, A., \& Sari, L. (2016). Effectiveness of mobile applications in vocabulary teaching. Contemporary Educational Technology, 7(1), 47-59.Available at: https://doi.org/10.30935/cedtech/6162.

Candry, S., Deconinck, J., \& Eyckmans, J. (2018). Written repetition vs. oral repetition: Which is more conducive to L2 vocabulary learning? Journal of the European Second Language Association, 2(1), 72-82.Available at: https://doi.org/10.22599/jesla.44.

Chang, Y.-H., Liu, T.-C., \& Paas, F. (2018). Cognitive resources allocation in computer-mediated dictionary assisted learning: From word meaning to inferential comprehension. Computers \& Education, 127, 113-129.Available at: https://doi.org/10.1016/j.compedu.2018.08.013.

Chen, Z. (2016). Language learning strategies based on the educational concept of innovation and entrepreneurship. Open Access Library Journal, 3, 1-6.Available at: https://doi:10.4236/oalib.1102780.

Deris, F., \& Shukor, N. (2019). Vocabulary learning through mobile apps: A phenomenologi-cal inquiry of student acceptance and desired apps features. International Association of Online Engineering, 13(7), 129-140.Available at: https://doi.org/10.3991/ijim.v13io7.10845

Ducar, C., \& Schocket, D. H. (2018). Machine translation and the L2 classroom: Pedagogical solutions for making peace with Google translate. Foreign Language Annals, 51(4), 779-795.Available at: https://doi.org/10.1111/flan.12366.

Eppard, J., Hojeij, Z., Ozdemir-Ayber, P., Rodjan-Helder, M., \& Baroudi, S. (2019). Using mobile learning tools in higher education: A UAE case. International Journal of Interactive Mobile Technologies, 13(11), 51-69.Available at: https://doi.org/10.3991/ijim.v 13i1 1.10823.

Farashaiyan, A., \& Tan, K. H. (2012). A cross-cultural comparative study of gratitude strategies between Iranian and Malaysian postgraduate students. Asian Social Science, 8(7), 139-148.Available at: http://doi.org/10.5539/ass.v8n7p139.

Giannetti, T. R. (2016). Google translate as a resource for writing. M.S. Thesis, St. John Fisher Col-lege.

González Fernández, B., \& Schmitt, N. (2015). How much collocation knowledge do L2 learn-ers have? The effects of frequency and amount of exposure. ITL-International Journal of Applied Linguistics, 166(1), 94-126.Available at: https://doi.org/10.1075/itl.166.1.03fer.

Graesser, A. C., McNamara, D. S., Cai, Z., Conley, M., Li, H., \& Pennebaker, J. (2014). Coh-Metrix measures text characteristics at multiple levels of language and discourse. The Elemen-tary School Journal, 115(2), 210-229.Available at: https://doi.org/10.1086/678293.

Groves, M., \& Mundt, K. (2015). Friend or foe? Google translate in language for academic purposes. English for Specific Purposes, 37, 112121.Available at: https://doi.org/10.1016/j.esp.2014.09.001.

Gu, Y., \& Johnson, R. K. (1996). Vocabulary learning strategies and language learning out-comes. A Journal of Research in Language Studies, 46(4), 643-679.Available at: https://doi.org/10.1111/j.1467-1770.1996.tbo1355.x.

Hsiao, I. Y., Lan, Y.-J., Kao, C.-L., \& Li, P. (2017). Visualization analytics for second language vocabulary learning in virtual worlds. Journal of Educational Technology \& Society, 20(2), 161-175.

Josefsson, E. (2011). Contemporary approaches to translation in the classroom: A study of students' attitudes and strategies. Retrieved from: http://du.diva-portal.org/smash/get/diva2:519125/FULLTEXTo1.pdf.

Kruk, M., \& Zawodniak, J. (2018). Boredom in practical English language classes: Insights from interview data. Interdisciplinary Views on the English Language, Literature and Culture, 177-191.

Kukulska-Hulme, A., \& Traxler, J. (2005). Mobile teaching and learning. In Mobile Learning: A handbook for educators and trainers (pp. 2544). Oxon: Routledge.

Lin, C. M., \& Wu, C. (2016). Idea sharing: Do students learn better through a more entertain-ing way? The case of Taiwan EFL students. PASAA: Journal of Language Teaching and Learning in Thailand, 51, 269-280.

Maguire, M., \& Delahunt, B. (2017). Doing a thematic analysis: A practical, step-by-step guide for learning and teaching scholars. All Ireland Journal of Higher Education, 9(3), 3351-33514.

Nakata, T., \& Webb, S. (2016). Does studying vocabulary in smaller sets increase learning. Studies in Second Language Acquisition, 38(3), 523552.Available at: https://doi.org/10.1017/S0272263115000236.

Oktaviana, F. (2018). A naturalistic study: English instruction at English course in Kampung Inggris. Loquen: English Studies Journal, 11(1), $40-62$. 
Pavlik, J. V. (2015). Fueling a third paradigm of education: The pedagogical implications of digital, social and mobile media. Contemporary Educational Technology, 6(2), 113-125.Available at: https://doi.org/10.30935/cedtech/6143.

Philip, B., Tan, K. H., \& Jandar, W. (2019). Exploring teacher cognition in Malaysian ESL classrooms. 3L: Language, Linguistics, Literature ${ }^{\text {, }}$ 25(4), 156-178.Available at: http://doi.org/10.17576/3L-2019-2504-10.

Rafiq, K. M., Hashim, H., Yunus, M. M., \& Norman, H. (2020). ìSPEAK: Using mobile-based online learning course to learn English for the workplace. International Journal of Interactive Mobile Technologies, 14(8), 19-31.Available at: https://doi.org/10.3991/ijim.v14io8.13185

Saigh, K., \& Schmitt, N. (2012). Difficulties with vocabulary word form: The case of Arabic ESL learners. System, 40(1), 24-36.Available at: https://doi.org/10.1016/j.system.2012.01.005.

Sanaoui, R. (1995). Adult learners' approaches to learning vocabulary in second languages. The Modern Language Journal, 79(1), 1528.Available at: https://doi.org/10.2307/329390.

Saran, M., \& Seferoğlu, G. (2010). Supporting foreign language vocabulary learning through multimedia messages via mobile phones. Hacettepe University Journal of Education, 38, 252-266.

Shuib, M., Abdullah, A., Azizan, S. N., \& Gunasegaran, T. (2015). Designing an intelligent mobile learning tool for grammar learning (iMoL). International Journal of Interactive Mobile Technologies, 9(1), 41-46.Available at: http://dx.doi.org/10.3991/ijim.v9i1.4238.

Stockwell, G. (2010). Using mobile phones for vocabulary activities: Examining the effect of platform. Language Learning E̊ Technology, 14(2), 95-1 10.Available at: http://dx.doi.org/10125/44216.

Stockwell, G., \& Liu, Y. C. (2015). Engaging in mobile phone-based activities for learning vocabulary: An investigation in Japan and Taiwan. CALICO Journal, 32(2), 299-322.Available at: https://doi.org/10.1558/cj.v32i2.25000.

Suwantarathip, O., \& Orawiwatnakul, W. (2015). Using mobile-assisted exercises to support students' vocabulary skill development. Turkish Online Journal of Educational Technology, 14(1), 163-171.

Tan, K. H., Farashaiyan, A., Sahragard, R., \& Faryabi, R. (2020). Implications of English as an international language for language pedagogy. International Journal of Higher Education, 9(1), 22-31.Available at: 10.5430/ijhe.v9n 1p22.

Tan, K. H., Woods, P., Azman, H., Abdullah, I. H., Hashim, R. S., Abdul Rahim, H., \& Kosem, I. (2020). COVID-19 insights and linguistic meth-ods. 3L: The Southeast Asian Journal of English Language Studies, 26(2), 1-23.Available at: http://dx.doi.org/10.17576/3L2020-2602-01.

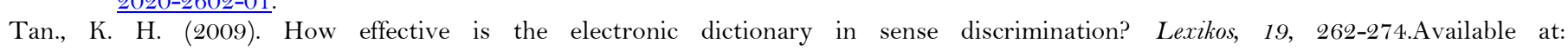
https://doi.org/10.5788/19-0-439.

Wijaya, I., Bakri, R., Wutun, A., Fitriani, F., \& Mattoliang, A. (2019). The effectiveness of mobile learning based android in learning English vocabularies. International Journal of Interactive Mobile Technologies, 13(12), 226-235.Available at: https://doi.org/10.3991/ijim.v13i12.11167.

Xie, X. (2010). Why are students quiet? Looking at the Chinese context and beyond. ELT Journal, 64(1), 10-20.Available at: https://doi.org/10.1093/elt/ccpo60. 